\title{
The Current Situation of China's Attitude to Legislation of Homosexuality
}

\author{
Liu Xinghan \\ Chongqing Medical University, Chongqing City, 400016, China
}

Keywords: homosexuality; legislation; protection; necessity;

\begin{abstract}
In all ages, homosexuality problems always exist objectively, and people didn't face up to them until the end of the 20th century. In 1989, Denmark became a country that protected homosexuality in legislative forms. In the last more than 20 years, many countries have protected homosexuality through legislation successively, thus it can be said that legislative protection has been an irresistible trend. It is of important significance to legislate homosexuality, concern the vulnerable group in law and manage homosexual person with legislation. However, the construction of a legal system in China for homosexuality cannot be finished in one day, and China is still confronted with some problems and difficulties at present.
\end{abstract}

\section{Disputes about Homosexuality}

At present, China holds a conservative attitude to homosexuality and makes homosexuality decriminalized and non-pathological, but it does not admit any relationships between homosexual partners. Moreover, Chinese people have a low support to same-sex marriage. The opinion survey of 2014 indicated that Chinese people who supported same-sex marriage just made up 21\%. Although it had an increase of 5\% than that in 5 years ago, government should consider public opinions before promoting legalization of same-sex marriage. For disputable laws like same-sex marriage, if over half of the public objects them, it is hard to image that the government would have force to do. Even if over half of the public support it, it is not far from enough. Besides that the public and politicians are not prepared, I think homosexual people themselves are not prepared. Now, less than $2 \%$ of Chinese homosexual people confess to their parents and only $21 \%$ of interviewees said that their friends and relatives were homosexual people. At the current stage, even if the same-sex marriage is legalized, how many homosexual people dare to marry? Even friends and relatives have not come out, will they wear a headgear to marry? Moreover, the Chinese society is in the fierce transformation period, and there are many social problems and contradictions. In addition, homosexuality problems have not be regarded as an urgent problem for people in high levels, thus in the Two Sessions, the response "two look-ahead" was not strange. Furthermore, China has many loopholes in the aspect of sex education at present, which causes children dare not to ask problems, and adults avoid the problems and even blame and beat children, which is an intangible barrier for legalization of homosexuality.

\section{Necessity of Legislation for Homosexuality}

Generally speaking, possible harms of homosexuality include: sexual behaviors of homosexual people are often disordered, they change sex objects frequently, and they do not adopt protective measures for some reasons, thus they are easy to be infected by various sexually diseases like Aids; under the current mainstream culture, most homosexual people have the moral guilt, big psychological stress and weak bearing capacity; once they are confronted with some emotional problems, they are easy to have some behavioral out of control such as self-injury, suicide, people hurting on purpose and intentional injury; to meet their sexual desires, some homosexual people would carry out homosexual behaviors on teenagers through methods like cheat, lure by promise of gain, violence and threat, which would severely endanger physical and psychological health of teenagers; some homosexual people have homosexual acts in public places (including jail and labor rehabilitation camps), and whoredom activities of homosexual people do not stop under restrictions 
in some areas, which would ruin general mood of society; and under pressure of the world, some homosexual people select opposite-sex marriage to cheat heterosexuality, which are easy to have problems. Same-sex marriage is the stabilizer of social relations. Marriage is an important social mechanism to consolidate partners and standardize sex orders. And value of marriage to individuals and society is reflected by this. Therefore, it is demanded by the society to write same-sex marriage into marriage law, make clear that same-sex marriage enjoys same rights with opposite-sex marriage and stabilize same-sex marriage.

That the country admits legalization of same-sex marriage in law can be beneficial for the whole society to accept homosexuality and same-sex marriage and reduce improper discrimination so as to make homosexual partners have confidence to face with work and life, which can mobilize their initiative and creativity, create wealth for the society, and realize their own value while creating value for the society. Only through legislation and concern the special group from law can we improve consciousness of the public, improve tolerance level of the whole society and give them much concern, tolerance and care through unconscious influence.

\section{Conditions to Promote Legislation}

People form correct opinions. With social development and scientific progress, thought level of people also improves. Now, people have basically formed a correct opinion to homosexuality: homosexuality is not a disease but a difference of people in sexual preference, and various sex preferences are no good or bad. There are many theories about sex preference. In nowadays, most scientists agree than sex preference can be comprehensive results of several factors like environment, perception and biology. In brief, what is important is that we should realize sex preference varies with individuals. And some experts believed that homosexuality could be related to inheritance and genes. However, people just confirm homosexuality in definition but fail to accept homosexuality to enter into their life from inner heart.

In 2004, a survey of the Ministry of Public Health of China indicated that Chinese male homosexual people made up about $2-4 \%$ of the total population of males, thus it can be estimated that China has about $5 \sim 10$ million male homosexual people. The data indicated that China had a certain proportion of homosexual people, and with social development, the proportion has shown a rising tendency. Therefore, it has important significance for themselves, family and the whole society to concern the special group.

Same-sex marriage is a tendency in the worldwide. Social environment changes quickly. Up to now, 21 countries throughout the world has declared legislation of same-sex marriage and issued a series of laws. Moreover, the internal law also standardized homosexuality. In addition, although many countries and regions do not declare legislation of same-sex marriage, they protect legal rights of same-sex partners in varying degrees. Therefore, China has much experience to take a reference in legislation, and can totally form a complete legal system for homosexuality.

Media has a powerful impetus. Now, televisions and network often exposed the phenomenon that many tragedies can been seen since the homosexuality group is strongly rejected by parents, schools and the society, which also promotes people to reflect their attitudes and methods to homosexuality problems. Success of legislation of homosexuality, including establishment of protective regulations for homosexuality, can be beneficial for the homosexuality group to strive for due human rights and right of equality. In China, homosexual people should enjoy equal treatment and equal rights with other natural person, and formulation of relevant laws to protect rights and benefits of homosexual people is a response to constitutional assurance, respect for human rights, and protection of equality rights.

\section{Measures that the Country Should Adopt at Present}

The country should speed up the legislative process to protect and management the group effectively, and reduce social damages. And for the public, we should establish correct ideology and help them to strive for legal rights actively. The homosexuality group should enjoy rights and 
interests equal to heterosexuality people, and their human body would not be damaged and they are free to speak and act. Moreover, various local governments should take measures to propagandize sex knowledge education, encourage people have sex behaviors under protection and have regular physical examination, and remind people suffering from infectious diseases to take corresponding measures to prevent spreading of diseases. Taking a reference from legislative progress of European and American countries, China can give preference to admission of partnership and provide basic property rights and mutual correlation rights for major incidents. The registration admission mode for same-sex partners is a eclectic selection which can be accepted by most people and provide basic guarantee and stability to the homosexuality group. However, for other disputable legislative details, a lot of surveys and studies are needed to confirm how to make it coexist with the existing marriage law and manage conflicts.

\section{References}

[1] Q. H. He, S. P. Huang, Z. X. Huang, et al. Research Status and Development Trend of Intelligent Wheelchairs [J]. Robotics and Applications, 2003, (2): 12-16.

[2] H. S. Wang. Investigation on Disabling Factors and Rehabilitation of Persons with Disabilities in Dongshan District of Guangzhou City [J]. Liferatue and Information On Preventine Medicine, 2001.7 (2): 103-106.

[3] N. Yang. Research on Humanized Design of Multifunctional Electric Wheelchairs for the Elderly, [D]. Southwest Jiaotong University, 2015.

[4] F. H. Lu. Research and Analysis of Wheelchairs Climbing Stairs [D]. Northeastern University, 2007.

[5] Y. Ren. Intelligent Wheelchair Structure Design and Research [D]. Tianjin University of Science and Technology, 2009.

[6] Z. G. Chen, Manual Wheelchair Design and Research based on the Psychological Needs of the Disabled [D]. Southwest Jiaotong University, 2009. 